\title{
ПИРРОВА ПОБЕДА ГРЕЧЕСКОЙ ДИПЛОМАТИИ
}

Аннотация. Визит турецкого президента в Афины в конце 2017 года расценивался правящей в Греции партией как знаковое историческое событие. Символичность момента могла бы положить начало улучшению греко-турециких отношений. Однако уже сейчас можно констатировать, что в ближайшее время качественного изменения в отношениях Греции и Туриии не предвидится. Виной тому как слабая политическая воля к разрешению застарельх споров, так и отсутствие конструктивной повестки со стороны Греции по разрешению новых противоречий между двумя странами. Не принес визит желаемых дивидендов и Алексису Ципрасу, шансы которого сохранить за собой место премьер-министра постепенно снижаются.

Ключевые слова. Греция, Туричя, внешняя политика, дипломатия, парламентские выборы.

\section{Дипломатический прорыв}

Отсутствие кардинальных изменений в экономике и тяжелая ситуация в социальной сфере в Греции ставят под сомнение предвыборные лозунги СИРИЗЫ, равно как и перспективы выиграть предстоящие в 2019 году парламентские выборы. Опросы общественного мнения, проведенные Университетом Македонии в 2017 году, показали, что за партию гото-

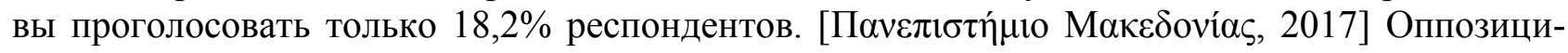
онная Новая демократия, напротив, продолжает увеличивать свой политический потенциал. За нее проголосовало бы на ближайших выборах уже 38,8\% респондентов.

На фоне ухудшения ситуации во внутренней политике греческий премьер-министр Алексис Ципрас решил сфокусироваться на дипломатических достижениях. На повестке дня оказались две ключевые для греческого общества темы - спор о наименовании с Бывшей югославской республикой Македония и греко-турецкие отношения. И если первый имеет все шансы на скорейшее разрешение, то на восточном направлении каких-либо существенных изменений в отношениях между странами не наблюдается.

Стагнацию в греко-турецких отношения мог бы изменить визит президента Турции Реджепа Эрдогана в Афины в начале декабря 2017 года. Стоит отметить, что это стало знаковым событием в отношениях между двумя странами, поскольку до этого визиты глав государств были крайне редким явлением. Так, последний визит президента Турции состоялся в ноябре 1952 года, когда Махмуд Джеляль Баяр приехал после того, как обе страны вступили в НАТО. При этом последний визит греческого руководства в Анкару состоялся в 2008 году, а тогдашний премьер-министр Костас Караманлис стал первым главой государства, посетивший Турцию за без малого 40 лет. Очевидно, что приезд турецкого президента можно назвать дипломатическим прорывом Алексиса Ципраса.

Весьма интересна риторика официальных встреч, которые проводились в рамках визита Реджепа Эрдогана. Несмотря на формальный призыв последнего к дальнейшему укреп-

(C) Зеликсон Денис Игоревич - кандидат политических наук, стариий научный сотрудник Института Европь РАН. Адрес: 125009, Россия, Москва, ул. Моховая, д. 11, cmp. 3; e-mail: dzelix@gmail.com

DOI: http://dx.doi.org/10.15211/vestnikieran220189 
лению военных, торговых и политических связей [Daily Sabah, 2017], основные тезисы турецкого президента были связаны с существующими проблемами в двухсторонних отношениях, а также резко негативной оценкой текущего состояния дел. В первую очередь критика касалась акватории Эгейского моря и мусульманского меньшинства, проживающего на территории Греции. Турецкий президент очередной раз призвал к пересмотру Лозаннского мирного договора 1923 года, который фактически сделал Турцию проигравшей стороной. [H

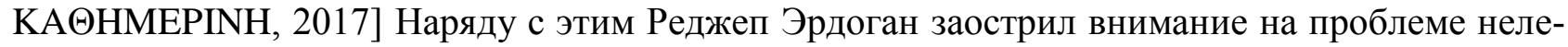
гальной миграции, негативно высказавшись в сторону Евросоюза, выделившего только €850 млн вместо запланированных €3 млрд на решение вопроса с тремя миллионами беженцев, находящихся в настоящий момент в Турции. [The New York Times, 2017]

В свою очередь, греческая сторона в привычной для себя манере напомнила про принцип pacta sunt servanda, которым должны руководствоваться стороны. Отмечая значимость греко-турецких отношений, президент Греции Прокопис Павлопулос отметил, что Лозаннский договор является фундаментом для дружбы и не требует пересмотра или расторжения. [Reuters, 2017] Ровно об этом же сказал на пресс-конференции и Алексис Ципрас, добавив, что для пересмотра договора необходимо как минимум позвать всех его участников, коих сегодня насчитывается 11 , так что речь о каких-либо изменениях идти не может. [Greek prime minister office, 2017]

Примечательно, что визит бы фактически лишен конструктивной программы для обсуждения между главами государств. Дело обошлось и без полноценных обсуждений между представителями министерств или бизнес сообщества. По сути, это был лишь символический визит, на котором стороны озвучили то, что до этого было понятно всем.

Взаимные выпады, прозвучавшие в ходе визита, весьма недвусмысленно говорили о том, что качественного прорыва в греко-турецких отношениях ожидать не приходится. Со стороны академических кругов звучали еще более резкие оценки текущего состояние связей между странами. Отмечалось, что страны находятся в состоянии высокой напряженности в отношениях и не имеют никаких предпосылок для их улучшения. [The Economist, 2017]

\section{Предпосылки прорыва}

Отношения с Турцией являются не только одним из ключевых векторов внешней политики Греции, но и традиционной темой для обсуждения в греческом обществе. В отличие от более консервативных сфер государственного управления, например, военной или внешнеэкономической, дипломатическая деятельность в большей степени связана с общественным мнением. Она в определенной степени реагирует на запросы общества и в какой-то степени делает власть ближе к народу за счет освящения дипломатических контактов в СМИ.

Дипломатический прорыв был необходим Алексису Ципрасу, поскольку в греческом обществе появился отчетливый запрос на улучшение отношений с Турцией. Проведенные опросы элит, представителей власти и общественного мнения в 2015 показали, что все за исключением военных поддерживают политику сближения между странами, хотя и при этом не испытывают особого доверия к Турции. [Ifantis, Triantaphyllou, Kotelis, 2015] Более поло- 
вины опрошенных оценивали текущий уровень двусторонних отношений как благоприятный. Для сравнения: в середине 1990-х годов 68,3\% греческих граждан видели в Турции одну из основных угроз для безопасности Греции. [Valinakis, Nikolaou, 1995]

Улучшению греко-турецких отношений способствовали и контакты на высшем уровне в рамках High-Level Cooperation Council. В 2013 году на второй сессии было подписано 25 разнообразных двусторонних соглашений, а также провозглашен принцип «win-win» в двусторонних отношениях. На третьей сессии в 2014 году была подписана совместная декларация, закладывающая перспективы сотрудничества в сфере энергетики, внешней торговли, транспорта и других отраслях. [Joint Declaration, 2014] Однако после этого активная фаза сотрудничества на уровне министерств и бизнес элит прекратилась, что позволяло говорить о необходимости возобновления подобного рода контактов между странами.

Дипломатический уровень, по всей видимости, был выбран и по причине того, что добиться позитивных результатов на нем было бы гораздо проще, чем в разрешении какихлибо внешнеполитических задач. Так, основополагающие векторы внешней политики Греции, включая греко-турецкие отношения, в условиях ее европеизации вышли за пределы непосредственной национальной компетенции и во многом были переданы на более высокий европейский уровень принятия решений. [Stavridis, 2018] В такой ситуации реальные внешнеполитические достижения требуют огромного количества ресурсов. Тем более, что восточный вектор внешней политики Греции можно охарактеризовать как наиболее энергоемкое. [Lesser et al., 2001]

\section{Неудавшаяся дипломатия}

Выбор момента для приглашения турецкого президента в Афины был оправдан для Алексиса Ципраса. Так, у него все еще есть время для повышения своей популярности перед очередными парламентскими выборами. Наряду с этим греко-турецкие отношения осложнены не только старыми проблемами, но и новыми противоречиями. Встреча глав двух государств могла бы положить начало нового диалога между Грецией и Турцией. В случае удачного стечения обстоятельств греческий премьер-министр мог бы отобрать изрядную порцию сторонников у своих конкурентов - Новой демократии.

К традиционным спорным вопросам греко-турецких отношений относится акватория Эгейского моря. В частности, камнем преткновения является вопрос о принадлежности островов Имия (Кардак). Уже вполне обычным делом стало нарушение территориальных границ Греции турецкими морскими и воздушными судами. Стоит отметить, что прямые военные столкновения из-за островов со значительной степенью вероятности исключены, а вот греческое общество очень резко реагирует на сообщения в СМИ о таких нарушениях.

Классической проблемной точкой является Кипр, недавние события вокруг которого полностью нивелировали те позитивные сдвиги, которые удалось добиться во время переговоров об объединении острова. Планы по геологоразведке и разработке углеводородных месторождений на шельфе Республики Кипр вызвали резкую милитаристскую риторику и наращивание военного присутствия со стороны Турции. Подобное поведение не могло остаться 
незамеченным в Греции, официальные лица которой напрямую дали понять, что целиком и полностью поддерживают суверенитет Кипра. Осуждение чрезмерной турецкой активности было и со стороны партнеров по НАТО.

К новым проблемам можно отнести отказ Верховного суда Греции экстрадировать восемь турецких офицеров, попросивших политическое убежище у Афин после провала военного переворота в Турции в 2016 году. Подобное решение было воспринято турецкой стороной как политическое и обострило и без того напряженные отношения между странами. В свою очередь, Турция продолжает удерживать в заключении двух греческих солдат, которые нарушили территориальную границу около города Эдирне в марте 2018 года.

Фактическое отсутствие продуманного предложения со стороны Греции по решению данных проблем или хотя бы какой-то конструктивной повестки дня для обсуждения с турецким президентом вызвало обратный эффект. Так, по опросам греческого населения, проведенным в апреле 2018 года, 81\% респондентов отмечают ухудшение греко-турецких отно-

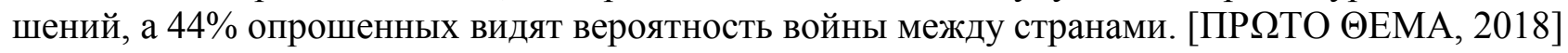

По всей видимости, исторически значимое по своему масштабу событие оказалось дипломатическим прорывом только на бумаге. В отличие от традиционных практик греческой дипломатии визиту Реджепа Эрдогана не предшествовали хоть какие-нибудь значимые контакты на уровне министерств или бизнес-элиты. А сам визит оказался на поверку исключительно показательным без какого-либо важного содержания.

При этом критика как со стороны оппозиционных СМИ, так и со стороны турецких властей не позволили Алексису Ципрасу получить ожидаемых дивидендов. Необходимо отметить, что Реджеп Эрдоган привез с собой в Афины порцию критики для своих греческих коллег и откровенно высказался намерениях Турции лучше отстаивать свои интересы в отношениях с Грецией. Вероятно, что символический момент был упущен, а в продолжении нас ждет лишь ухудшение двусторонних отношений между странами, которые на данный момент находятся в состоянии «холодного мира».

\section{Список литературы/References}

Daily Sabah. 19.12.2017. Режим доступа: https://www.dailysabah.com/oped/2017/12/19/what-came-from-erdogans-visit-to-athens (Дата обращения: 30.04.2018.)

Ifantis K., Triantaphyllou D., Kotelis A. National Role and Foreign Policy: An Exploratory Study of Greek Elites' Perceptions towards Turkey. Hellenic Observatory Discussion Papers on Greece and Southeast Europe. Paper №94. 2015. Режим доступа: http://www.lse.ac.uk/HellenicObservatory/Assets/Documents/Publications/GreeSE-Papers/GreeSE-No94.pdf (Дата обращения: 30.04.2018.)

Joint Declaration Between the Government of the Hellenic Republic and the Government of the Republic of Turkey. 05.12.2014. Режим доступа:

https://www.mfa.gr/images/docs/ellinotourkiko/joint\%20declaration.pdf (Дата обращения: 30.04.2018.) 
Greek prime minister office. A new chapter in the relations of our peoples on the basis of mutual respect and respect for international law. 07.12.2017. Режим доступа: https://primeminister.gr/en/2017/12/07/19010 (Дата обращения: 30.04.2018.)

Lesser I.O., Larrabee S.F., Zanini M., Vlachos-Dengler K. Greece’s New Geopolitics. Santa Monica: RAND, 2001. p. 137.

Reuters. 07.12.2017. Режим доступа: https://www.reuters.com/article/us-greece-turkeyerdogan/greece-and-turkey-trade-barbs-as-erdogan-visits-athens-idUSKBN1E10S9 (Дата обращения: 30.04.2018.)

Stavridis S. Greek parliamentarians and Greek foreign policy (2004-2014). Hellenic Observatory Discussion Papers on Greece and Southeast Europe. Paper №121. 2018. Режим доступа: http://www.lse.ac.uk/Hellenic-Observatory/Assets/Documents/Publications/GreeSE-

Papers/GreeSE-121.pdf (Дата обращения: 30.04.2018.)

The Economist. 14.12.2017. Режим доступа: https://www.economist.com/blogs/economistexplains/2017/12/economist-explains-8 (Дата обращения: 30.04.2018.)

The New York Times. 07.12.2017. Режим доступа: https://www.nytimes.com/2017/12/07/world/europe/erdogan-greece-turkey-visit.html (Дата обращения: 30.04.2018.) p. 326.

Valinakis Y., Nikolaou Y. Yearbook of Defense and Foreign Policy 1995. Athens: Eliamep,

H KA@HMEPINH. 08.12.2017 Режим доступа: http://www.ekathimerini.com/224005/article/ekathimerini/news/on-historic-trip-turkeys-erdoganmeets-muslims-in-greece (Дата обращения: 30.04.2018.)

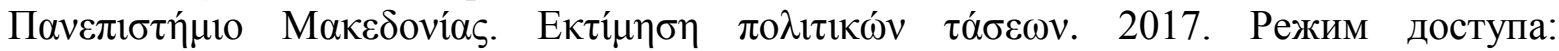

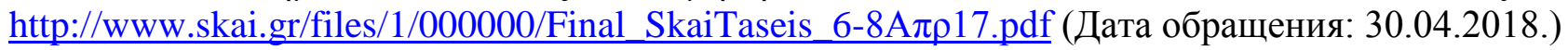

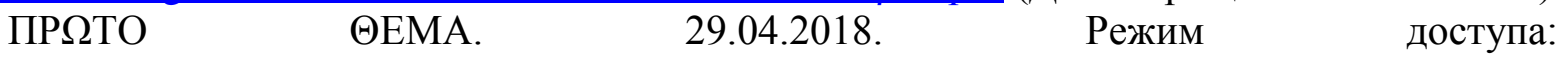
https://www.protothema.gr/politics/article/782935/ereuna-public-issue-i-athina-heirizetai-lathos-tissheseis-me-tin-tourkia-ektima-to-54/ (Дата обращения: 30.04.2018.)

\section{The Pyrrhic victory of Greek diplomacy}

Author. Zelikson D.I. PhD Candidate, Institute of Europe RAS, Address: 11-3, Mokhovaya street, 125993, Moscow, Russia. E-mail: dzelix@gmail.com

Abstract. The official visit of Turkish president in Athens has been recognized by Greek ruling party as the significant historical event. Symbolism of the visit may lead off an improvement of Greek-Turkish relations. However, for now it could be stated that a major breakthrough in relations between Greece and Turkey is not foreseeable. The problems are as a weak willpower for solving the old disputes, so the absence of agenda for resolving the new contradictions between both countries. The visit has not yielded any dividends for Alexis Tsipras, who is losing his chances to hold the prime minister office.

Keywords. Greece, Turkey, foreign policy, diplomacy, general elections.

DOI: http://dx.doi.org/10.15211/vestnikieran220189 